\title{
ARTICLE
}

Nutrition in acute and chronic diseases

\section{High proportion of thiamine deficiency in referred cancer patients with delirium: a retrospective descriptive study}

\author{
Hideki Onishi $\mathbb{D}^{1} \cdot$ Izumi Sato $^{2} \cdot$ Nozomu Uchida $^{3} \cdot$ Takao Takahashi $^{4} \cdot$ Daisuke Furuya $^{5} \cdot$ Yasuhiro Ebihara $^{6}$. \\ Akira Yoshioka ${ }^{7} \cdot$ Hiroshi Ito $^{8} \cdot$ Mayumi Ishida $\mathbb{D}^{9}$
}

Received: 15 April 2020 / Revised: 23 December 2020 / Accepted: 7 January 2021 / Published online: 29 January 2021

(c) The Author(s) 2021. This article is published with open access

\begin{abstract}
Background/Objectives Recent studies have revealed thiamine deficiency (TD) as a cause of delirium in cancer patients. However, the extent to which Wernicke encephalopathy is present and in what patients is not well understood.

Subjects/Methods In this retrospective descriptive study, we investigated referred cancer patients who were diagnosed with delirium by a psycho-oncologist to clarify the proportion of TD, the therapeutic effect of thiamine administration, and the factors involved in its onset.

Results Among 71 patients diagnosed with delirium by a psycho-oncologist, TD was found in $45 \%$ of the patients. Intravenous administration of thiamine led to a recovery in about $60 \%$ of these patients. We explored the factors associated with TD using a multivariable regression model with a Markov chain Monte Carlo imputation procedure. We found an association between TD and chemotherapy (adjusted odds ratio, 1.98 [95\% confidence interval, 1.04-3.77]); however, there were no significant associations between TD and the other factors we considered.

Conclusions TD is not particularly rare in delirium patients undergoing psychiatric consultation. The delirium was resolved in more than half of these patients by intravenous administration of thiamine. Oncologists should consider TD as a cause of delirium in cancer patients. Further prospective study is needed to clarify the relationship between TD and delirium in cancer patients.
\end{abstract}

Mayumi Ishida

mayumi_i@saitama-med.ac.jp

1 Department of Psycho-oncology, Saitama Medical University International Medical Center, 1397-1 Yamane, Hidaka City, Saitama 350-1298, Japan

2 Department of Pharmacoepidemiology, Graduate School of Medicine and Public Health, Kyoto University, Kyoto, Japan

3 Department of General Medicine, Ogano Town Central Hospital, Ogano, Japan

4 Department of Supportive Medicine, Saitama Medical University International Medical Center, Hidaka, Japan

5 Department of General Medicine, Saitama Medical University International Medical Center, Hidaka, Japan

6 Department of Laboratory Medicine, Saitama Medical University International Medical Center, Hidaka, Japan

7 Department of Clinical Oncology, Mitsubishi Kyoto Hospital, Kyoto, Japan

8 Ito Internal Medicine and Pediatric Clinic, Fukuoka, Japan

9 Department of Psycho-oncology, Saitama Medical University International Medical Center, Hidaka, Japan

\section{Introduction}

Delirium is one of the major problems arising during the course of cancer treatment. As this condition is common in patients with advanced cancer and is associated with increased complications and mortality, an examination of its causes in its early stages as well as therapeutic interventions is required [1]. However, delirium is often unrecognized or misdiagnosed by physicians [2]. According to a survey of cancer patients, delirium was missed in $50-60 \%$ of cases [3, 4]. In addition, recent studies have reported thiamine deficiency (TD) as a cause of delirium in cancer patients [5-9].

Thiamine is a water soluble vitamin and, in its biologically active form of thiamine pyrophosphate, is an essential coenzyme for oxidative metabolism [10]. This vitamin cannot be synthesized in vivo and depends on external intake. The recommended daily allowance of thiamine is $1.2 \mathrm{mg} /$ day for men and $1.1 \mathrm{mg} /$ day for women [11, 12]. Furthermore, the population reference intake is $0.4 \mathrm{mg} /$ $1000 \mathrm{kcal}$ [13]. However, since stores in the body are 
exhausted within 18 days [14], deficiency can occur when a patient experiences a loss of appetite lasting a few weeks.

Various issues have been highlighted regarding nutritional intake in cancer patients. A study comparing dietary intake in patients undergoing chemotherapy for gastric cancer before and at 6 months after the start of chemotherapy showed a significant decrease in vitamin B1, B6, and B12 intake, as well as significant decreases in the consumption of beef, low-fat milk, and raw vegetables [15]. A survey of patients receiving chemotherapy for breast cancer found problems with dietary intake in $80 \%$ of patients [16]. Patients with neuroendocrine tumors were found to have lower intake of vegetables, fruits, wine, seafood, and nuts, and increased intake of meat, butter, meat, margarine, soda, etc., compared to controls. In addition, patients with aggressive disease showed lower adherence to a Mediterranean diet.

A typical neuropsychiatric disorder associated with TD is Wernicke encephalopathy (WE), which is recognized by a classic triad of symptoms: mental status changes, ataxia, and ocular symptoms. This disease was previously seen as a common illness associated with alcoholism, but it can develop in association with any disease resulting in a loss of appetite [17]. Indeed, it is not a rare disease and, in a prospective necropsy study, the prevalence of the WernickeKorsakoff syndrome in Sydney, Australia was shown to be $2.1 \%$ of adults over the age of 15 years [18]. Recent research has shown that the disease is also common in cancer patients. Onset varies from initial chemotherapy treatment, to postsurgery, to treatment with anticancer drugs for recurrent cancer, to end-stage cancer [5-9, 19-21].

The treatment for $\mathrm{TD}$, including WE, involves the intravenous administration of thiamine [22] and, if it is detected early, patients can recover without any sequelae. However, failure to treat the condition early due to it being unrecognized or misdiagnosed can result in Korsakoff syndrome, leading to severe and irreversible brain damage [10]. The mortality rate for Korsakoff syndrome is as high as $17 \%$ [23]. However, WE is often overlooked or is misdiagnosed as another mental illness $[9,10,17,24]$ as the individual symptoms are not disease-specific, and only $16 \%$ cases present with all three classic symptoms of WE, with those without any of the three symptoms representing nearly $19 \%$ of cases [25]. Therefore, in cancer patients with delirium, early detection and treatment of TD is an important issue for preventing severe brain damage, such as that associated with Korsakoff syndrome, and maintaining the patient quality of life. However, the extent to which and in what patients WE is present is not well understood.

Therefore, we undertook this retrospective descriptive study of referred cancer patients who developed delirium, focusing on the proportion of those with TD and their characteristics.

\section{Methods}

\section{Participants and procedures}

\section{Study design and setting}

We conducted a retrospective descriptive study using electronic medical records (EMRs) for patients with cancer referred to the Department of Psycho-oncology, Saitama Medical University International Medical Center, and diagnosed with delirium between October 1st, 2014 and May 31th, 2018. The Cancer Center is in a university hospital with 400 beds that treats about 4800 new patients each year and is the highest volume cancer center in any Japanese university hospital. Our department handles about $5 \%$ of the patients who visit the Cancer Center.

\section{Subjects}

\section{Inclusion criteria}

We included patients with cancer aged 18 years or older who were diagnosed with delirium on consultation with a psycho-oncologist who was a psychiatrist (psycho-oncologist is a collective term for medical professionals and researchers specializing in the clinical treatment and research of cancer) with extensive experience with cancer patients. Delirium screening was performed for all $(n=$ 714) patients referred, the reason being that the doctor in charge often misdiagnoses delirium [26].

The criteria set in the Diagnostic and Statistical Manual of Mental Disorders 5th edition (DSM-V) were used to diagnose delirium [27]. These diagnostic criteria, published by the American Psychiatric Association, are the most commonly used diagnostic criteria around the world, and help resolve problems with the reliability of diagnosis among psychiatrists. These diagnostic criteria are also used as part of routine clinical care in psychiatric settings around the world. When a diagnosis of delirium could not be confirmed, we conducted multiple examinations and followups, and also conferred with psychological specialists who are also psycho-oncologists (MIs) experienced in treating cancer patients, before making a final diagnosis. All cases were finally determined to be delirium through consultation with psychological specialists (MIs).

\section{Exclusion criteria}

We excluded patients receiving oral or intravenous vitamin administration, those who met the DSM-V criteria for alcohol use disorders, those whose health status has deteriorated, those for whom blood collection was impossible, 
or those for whom, in the researcher's judgment, blood collection was inappropriate.

\section{Data collection from electrical medical records}

We collected data regarding each patient's background (age, gender, height, weight, primary site of cancer, preexisting disease, and Performance Status [PS]), history of cancer treatment [radiation/chemotherapy/surgery/hormone] within 2 months from the time of blood sampling for vitamin B1 measurement, and disappearance of the symptoms of delirium after vitamin B1 treatment from EMRs, and results of laboratory examinations (vitamin B1 level, albumin level, and lactate dehydrogenase [LDH] level), which were ordered as part of routine clinical care based on the judgment of the treating physicians at the time of referral or within a few days before consultation. Performance status (PS), as defined by the Eastern Cooperative Oncology Group criteria provides an objective index of a patient's physical functioning on a scale of 0 to 4 , with a higher score indicating greater physical condition deterioration ( $\mathrm{PS}=0$ indicates no symptoms, PS $=4$ indicates completely bedridden) [28]. Presence or absence of delirium was judged comprehensively from the description of delirium in the medical records and examination by the psycho-oncologist. Serum thiamine concentration was measured using highperformance liquid chromatography at an outside laboratory (SRL, Inc. Tokyo). This method is precise and rapid, and is less susceptible to factors that alter enzyme activity, while providing a more sensitive assay for screening TD in a clinical setting and for research purposes [29].

\section{Statistical analysis}

The sample size was determined to provide adequate power for the assessment of the outcomes of TD induced by chemotherapy. We expected a difference in the proportion of patients (0.35) with TD induced by chemotherapy. We calculated that a sample size of 60 patients (30 patients in each group) would provide $80 \%$ power to detect an odds ratio of 1.75 , using a two-sided type I error rate of 0.05 .

We calculated descriptive statistics to summarize the patients' background, history of cancer treatment and results of laboratory examinations. We set an albumin level under $3.9 \mathrm{~g} / \mathrm{dl}$ as representing low albumin, $\mathrm{LDH}$ under $212 \mathrm{U} / \mathrm{L}$ as low LDH, serum thiamine concentration under $<24 \mathrm{ng} / \mathrm{ml}$ as thiamine deficient, and BMI under $90 \%$ of average as low BMI. We then performed univariable and multivariable logistic regression analyses to investigate the factors associated with TD among the following factors: age, sex, BMI, $\mathrm{LDH}$, albumin, gastroenterological cancer, performance status, cancer treatment (radiation/chemotherapy/surgery/ hormone), and comorbidities (diabetes mellitus, high-blood pressure, and cardiac disorder). We imputed BMI, LDH, albumin, and PS when we estimated the adjusted odd ratios using the Markov chain Monte Carlo method (Yuan [Ed], Multiple imputation for missing data: Concepts and new development. Proceedings of the Twenty-Fifth Annual SAS Users Group International Conference; 2000). All statistical operations were performed with SAS statistical software version 9.4 for Windows (SAS Institute Inc., Cary, $\mathrm{NC}$, USA). All $\mathrm{p}$ values were two-sided, and the $\alpha$ level was set at 0.05 .

The ethical and scientific validity of this study was approved by the institutional review board of Saitama Medical University International Medical Center (18-080).

\section{Results}

During the study period, the number of consultation requests for cancer patients was 714, of which 143 were diagnosed with delirium.

Of these 143 patients diagnosed with delirium, 71 patients satisfied the eligibility criteria (Fig. 1). We excluded 72 patients for the following reasons; 52 were treated with thiamine, two were diagnosed with alcoholism, 14 had no blood test results, and four with thiamine levels regarded as outliers.

The study cohort comprised $66 \%$ male patients with a mean age (SD) of $69.6( \pm 10.4)$ years (Table 1$)$. Of the 71 patients, $45.1 \%(n=32)$ had TD. The mean age (SD) in patients with TD and patients with normal thiamine levels was $68.9(10.8)$ and $70.3(9.8)$, respectively. Also the mean albumin level (SD) was $3.0(0.6) \mathrm{g} / \mathrm{dL}$, and $3.3(0.7) \mathrm{g} / \mathrm{dL}$, mean LDH was 478.0(447.0) U/L and 396.0 (404.2) U/L, and mean BMI (SD) was 21.1 (3.3) and 20.6 (2.7), respectively. Patients with TD were more likely to have a BMI under $90 \%$ of average, to have gastroenterological cancer and comorbidities, and to have received cancer treatment within 2 months.

Intravenous administration of thiamine was performed for all TD patients $(n=32)$, with a recovery observed in $59.3 \%$ of the patients.

We found only an association between TD and chemotherapy (adjusted odds ratio, 1.98 [95\% confidence interval, 1.04-3.77]); however, there were no significant associations between TD and any of the other factors we considered (Table 2).

\section{Discussion}

In this retrospective descriptive study, we clarified the percentage of cancer patients with delirium who experienced TD as well as the patients' background 


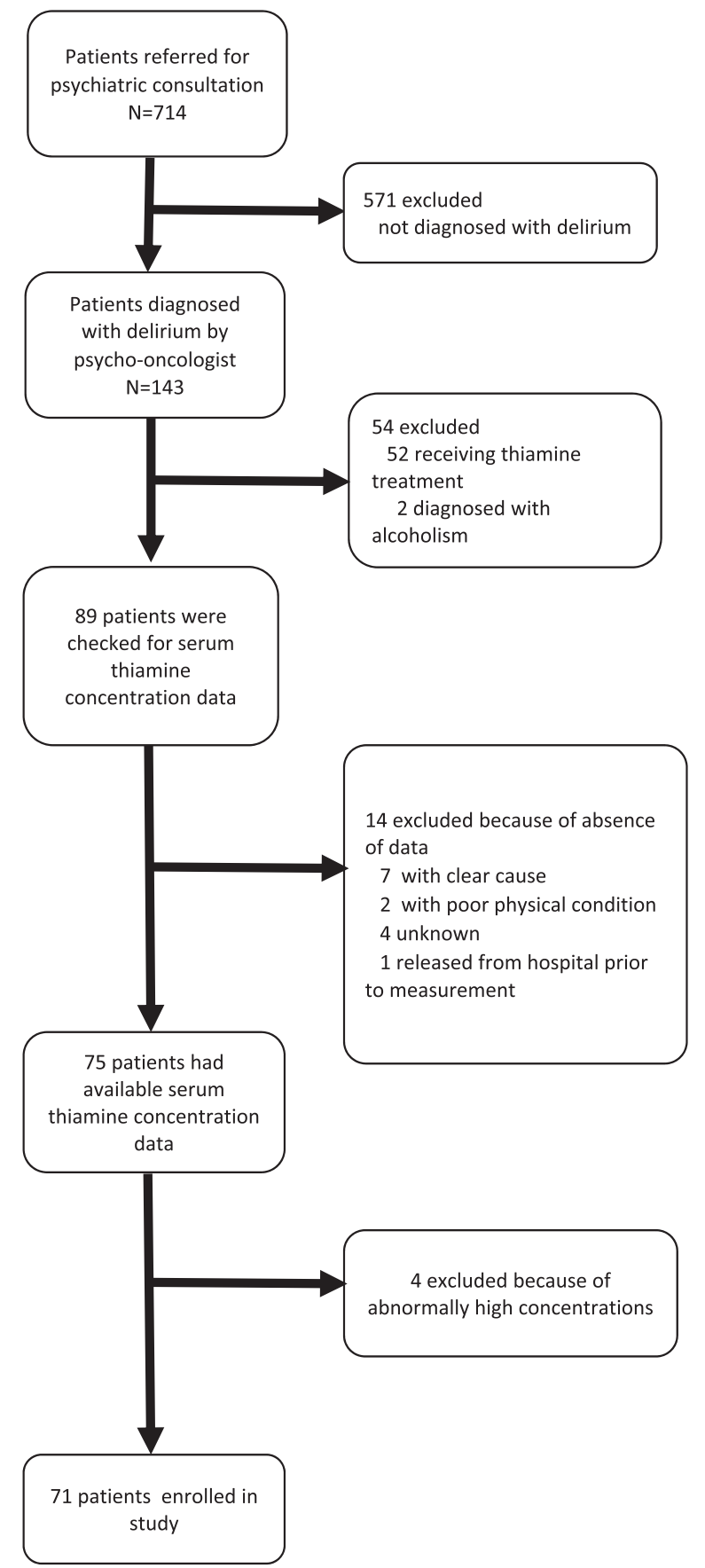

Fig. 1 Patient selection.

characteristics. We found TD in about $45 \%$ of cancer patients diagnosed with delirium who were referred for a psychiatric examination and had not received thiamine. The TD in these patients was associated with receiving chemotherapy two months prior to blood sampling. In addition, the symptoms of delirium were improved in half of these patients by the intravenous administration of thiamine. These results indicate that TD is not uncommon in referred cancer patients diagnosed with delirium.
Table 1 Patients' characteristics.

\begin{tabular}{|c|c|c|c|c|}
\hline \multirow[t]{2}{*}{ Variable } & \multicolumn{2}{|c|}{ Total $n=71$} & \multirow{2}{*}{$\begin{array}{l}\text { Thiamine } \\
\text { deficiency } \\
n=32 \\
\mathrm{n}(\%)\end{array}$} & \multirow{2}{*}{$\begin{array}{l}\text { Normal } \\
\text { Thiamine } \\
\text { level } n=39 \\
\mathrm{n}(\%)\end{array}$} \\
\hline & \multicolumn{2}{|l|}{$\overline{\mathrm{n}(\%)}$} & & \\
\hline Male & \multicolumn{2}{|l|}{$44(62.0)$} & $19(59.4)$ & $25(64.1)$ \\
\hline \multicolumn{5}{|c|}{ Age(years) } \\
\hline Mean & & $69.6(10.4)$ & $68.9(10.8)$ & $70.3(9.8)$ \\
\hline $\min -n$ & & $35-86$ & $35-86$ & $46-86$ \\
\hline \multicolumn{5}{|c|}{ Albumin $(n=65)$} \\
\hline$<4.5 \mathrm{~g}$ & & $57(87.7)$ & $28(90.3)$ & $29(78.4)$ \\
\hline Mean & & $3.1(0.7)$ & $3.0(0.6)$ & $3.3(0.7)$ \\
\hline $\min -n$ & & $1.9-4.7$ & $1.9-4.6$ & $1.9-4.7$ \\
\hline \multicolumn{5}{|c|}{$\mathrm{LDH}(\mathrm{n}=65)$} \\
\hline$<212$ & & $17(26.2)$ & $7(22.6)$ & $10(29.4)$ \\
\hline Mean & & $\begin{array}{l}422.5 \\
(432.2)\end{array}$ & $\begin{array}{l}478.0 \\
(477.0)\end{array}$ & $396.0(404.2)$ \\
\hline $\min -n$ & & $137-2,125$ & $137-2,125$ & $138-2,098$ \\
\hline \multicolumn{5}{|c|}{ Body Mass Inde(BMI) $(n=62)$} \\
\hline$<90 \%$ & & $34(54.8)$ & $18(60.0)$ & $16(50.0)$ \\
\hline Mean & & $20.7(3.1)$ & $21.1(3.3)$ & $20.6(2.7)$ \\
\hline $\min -n$ & & $12-30$ & $12-30$ & $15-29$ \\
\hline Gastr & gical cancer & $14(19.7)$ & $8(25.0)$ & $6(15.4)$ \\
\hline \multicolumn{5}{|c|}{ Performance status $(n=67)$} \\
\hline 0 & & $3(4.5)$ & $0(0.0)$ & $3(7.9)$ \\
\hline 1 & & $6(9.0)$ & $2(6.9)$ & $4(10.5)$ \\
\hline 2 & & $18(26.9)$ & $9(31.0)$ & $9(23.7)$ \\
\hline 3 & & $29(43.3)$ & $13(44.8)$ & $16(42.1)$ \\
\hline 4 & & 11(16.4) & $5(17.2)$ & $6(15.8)$ \\
\hline \multicolumn{5}{|c|}{ Cancer treatment } \\
\hline $\begin{array}{l}\text { Recei } \\
\text { two n }\end{array}$ & nent within & $52(73.2)$ & $27(84.4)$ & $25(64.1)$ \\
\hline Horm & & $3(4.2)$ & $2(6.3)$ & $1(2.6)$ \\
\hline Radia & & $14(19.7)$ & $6(18.8)$ & $8(20.5)$ \\
\hline Chem & & $31(43.7)$ & $20(62.5)$ & $11(28.2)$ \\
\hline Surge & & 14(19.7) & $6(18.8)$ & $8(20.5)$ \\
\hline \multicolumn{5}{|c|}{ Comorbidity } \\
\hline Diabe & & $8(11.3)$ & $4(12.5)$ & $4(10.3)$ \\
\hline High- & essure & $16(22.5)$ & $9(21.9)$ & $7(17.9)$ \\
\hline Cardi & & $5(7.0)$ & $3(6.3)$ & $2(5.1)$ \\
\hline
\end{tabular}

BMI $($ Body Mass Index $)=\mathrm{kg} / \mathrm{m}^{2}$, where $\mathrm{kg}$ is a person's weight in kilograms and $\mathrm{m}^{2}$ is their height in meters squared.

This study also clarified several problems.

Thiamine deficiency was found in $45 \%$ of the delirium patients enrolled. A study of referred patients examined at cancer center hospital in the United States found that 55\% had TD [30]. Thus, our findings supported those of the US study, and appear to indicate that TD may not be recognized by oncologists as the cause of delirium. 
Table 2 Odds ratio for thiamine deficiency among patients with delirium.

\begin{tabular}{lllllll}
\hline variable & OR & $95 \% \mathrm{CI}$ & $P$ value & aOR & $95 \% \mathrm{CI}$ & $P$ value \\
\hline Age & 0.99 & $(0.94-1.04)$ & 0.62 & 1.00 & $(0.93-1.06)$ & 0.9 \\
Sex (ref = female) & 0.57 & $(0.21-1.54)$ & 0.27 & 0.67 & $(0.36-1.25)$ & 0.21 \\
Albumin (ref =<4.5 g/dL) & 0.39 & $(0.08-1.50)$ & 0.19 & 0.56 & $(0.24-1.31)$ & 0.18 \\
BMI (ref =<90\% average) & 1.17 & $(0.42-3.24)$ & 0.77 & 1.29 & $(0.69-2.42)$ & 0.42 \\
LDH (ref = >211 U/L) & 1.00 & $(1.00-1.00)$ & 0.33 & 1.33 & $(0.65-2.73)$ & 0.44 \\
Gastroenterological cancer & 1.83 & $(0.57-6.24)$ & 0.31 & 1.53 & $(0.68-3.45)$ & 0.31 \\
Performance status(ref =0) & 1.29 & $(0.79-2.17)$ & 0.32 & 1.32 & $(0.73-2.37)$ & 0.36 \\
Hormone therapy & 2.53 & $(0.23-56.01)$ & 0.46 & 2.32 & $(0.51-10.63)$ & 0.28 \\
Radiation therapy & 0.89 & $(0.26-2.90)$ & 0.85 & 0.9 & $(0.43-1.89)$ & 0.79 \\
Chemotherapy & 4.24 & $(1.60-11.92)$ & 0.00 & 1.98 & $(1.04-3.77)$ & 0.04 \\
Surgery & 0.89 & $(0.26-2.90)$ & 0.85 & 0.85 & $(0.34-2.12)$ & 0.73 \\
Diabetic mellitus & 1.25 & $(0.27-5.72)$ & 0.77 & 1.14 & $(0.37-3.55)$ & 0.82 \\
High-blood pressure & 1.79 & $(0.58-5.68)$ & 0.31 & 1.35 & $(0.65-2.76)$ & 0.42 \\
Cardiac disorder & 1.91 & $(0.30-15.26)$ & 0.49 & 1.62 & $(0.47-5.58)$ & 0.45 \\
\hline
\end{tabular}

$O R$ odd ratio, $a O R$ adjusted odd ratio, $B M I$ body mass index, $L D H$ lactate dehydrogenase.
Furthermore, we found an association between TD and chemotherapy. The reason why chemotherapy is related to TD is related to the patients' medical condition and treatment. Based on the previous literature and our clinical observations [10, 14, 31-33], we hypothesized that an appetite loss lasting more than 2 weeks, a side effect of chemotherapy, which also involves the over utilization and destruction of thiamine, leads to TD. However, the other factors we considered were not associated with TD. As this study was a retrospective descriptive study, it cannot be ruled out that the failure to collect blood in all cases may have had an effect. It seems that the number of patients diagnosed with TD in this study was insufficient for meaningful statistical analysis. It will be necessary to perform a prospective study in the future.

In this study, patients with delirium were considered, but some patients with TD do not exhibit delirium [24, 25, 30, 34, 35]; therefore, even more patients with TD may be identified in future detailed investigations.

The limitations of this study include that fact that it was a single-center study targeting patients with delirium who consulted a psychiatrist. This study has referral bias as it was focused on cases referred for psychiatric consultation. Thus, the ability to draw generalizations from this study is also limited. Another limitation in this study was that we were able to identify patients with alcohol dependence, but were unable to clarify their alcohol intake in detail. Furthermore, serum thiamine concentration was not measured in all patients who received consultations. It might be that only patients displaying relatively severe symptoms received blood tests. In addition, there may be a lack of measurement of confounding factors related to TD, as we did not consider the history of medication use and all comorbidities. Further investigation is still needed using a database, including variables such as medication use and comorbidities, for a large population from multiple centers.

In conclusion, it was found that TD is not particularly rare in delirium patients undergoing psychiatric consultation. Further research is expected to reveal the actual situation regarding TD in cancer patients, enabling the prevention of WE and Korsakoff syndrome, and contributing to improved quality of life for cancer patients.

Acknowledgements We would like to thank Dr. Kunihiko Ishitani (Higashi Sapporo Hospital) for his valuable advice in advancing this research.

Funding This work was supported by JSPS KAKENHI (Grant Number JP19K11722).

Author contributions MI, NU, IS, TT, DF, YE, HI, and HO conceived and designed the study; MI, IS, AY, and HO carried out the study, and managed and analyzed data; IS performed the statistical analysis; HO, MI and IS drafted the manuscript; TT, FD, AY, HI, and HE reviewed the manuscript. All authors read and approved the final manuscript.

\section{Compliance with ethical standards}

Conflict of interest The authors declare that they have no conflict of interest.

Publisher's note Springer Nature remains neutral with regard to jurisdictional claims in published maps and institutional affiliations.

Open Access This article is licensed under a Creative Commons Attribution 4.0 International License, which permits use, sharing, adaptation, distribution and reproduction in any medium or format, as long as you give appropriate credit to the original author(s) and the source, provide a link to the Creative Commons license, and indicate if changes were made. The images or other third party material in this article are included in the article's Creative Commons license, unless indicated otherwise in a credit line to the material. If material is not 
included in the article's Creative Commons license and your intended use is not permitted by statutory regulation or exceeds the permitted use, you will need to obtain permission directly from the copyright holder. To view a copy of this license, visit http://creativecommons. org/licenses/by/4.0/.

\section{References}

1. Lawlor PG, Gagnon B, Mancini IL, Pereira JL, Hanson J, SuarezAlmazor ME, et al. Occurrence, causes, and outcome of delirium in patients with advanced cancer: a prospective study. Arch Intern Med. 2000;160:786-94. e-pub ahead of print 2000/03/29.

2. Inouye SK. The dilemma of delirium: clinical and research controversies regarding diagnosis and evaluation of delirium in hospitalized elderly medical patients. Am J Med. 1994;97:278-88. epub ahead of print 1994/09/01. https://doi.org/10.1016/0002-9343 (94)90011-6.

3. Fang CK, Chen HW, Liu SI, Lin CJ, Tsai LY, Lai YL. Prevalence, detection and treatment of delirium in terminal cancer inpatients: a prospective survey. Jpn J Clin Oncol. 2008;38:56-63. https://doi. org/10.1093/jjco/hym155. e-pub ahead of print 2008/02/02.

4. Inouye SK, Foreman MD, Mion LC, Katz KH, Cooney LM Jr. Nurses' recognition of delirium and its symptoms: comparison of nurse and researcher ratings. Arch Intern Med. 2001;161:2467-73. https://doi.org/10.1001/archinte.161.20.2467. e-pub ahead of print 2001/12/01.

5. Barbato M, Rodriguez PJ. Thiamine deficiency in patients admitted to a palliative care unit. Palliat Med. 1994;8:320-4. https://doi.org/10.1177/026921639400800408. e-pub ahead of print 1994/10/01.

6. Onishi H, Kawanishi C, Onose M, Yamada T, Saito H, Yoshida A, et al. Successful treatment of Wernicke encephalopathy in terminally ill cancer patients: report of 3 cases and review of the literature. Support Care Cancer. 2004;12:604-8. https://doi.org/ 10.1007/s00520-004-0637-y. e-pub ahead of print 2004/05/14.

7. Onishi H, Ishida M, Kagamu H, Murayama Y, Kobayashi K, Sato I et al. Wernicke encephalopathy in a lung cancer patient during treatment with nivolumab. Palliat Support Care 2018: 1-3. e-pub ahead of print 2018/08/04; https://doi.org/10.1017/ s1478951518000469.

8. Isenberg-Grzeda E, Hsu AJ, Hatzoglou V, Nelso C, Breitbart W Palliative treatment of thiamine-related encephalopathy (Wernicke's encephalopathy) in cancer: a case series and review of the literature. Palliat Support Care 2014: 1-9. e-pub ahead of print 2014/10/24; https://doi.org/10.1017/s1478951514001163.

9. Isenberg-Grzeda E, Kutner HE, Nicolson SE. Wernicke-Korsakoff-syndrome: under-recognized and under-treated. Psychosomatics. 2012;53:507-16. https://doi.org/10.1016/j.psym.2012.04. 008. e-pub ahead of print 2012/11/20.

10. Sechi G, Sechi E, Fois C, Kumar N. Advances in clinical determinants and neurological manifestations of B vitamin deficiency in adults. Nutr Rev. 2016;74:281-300. https://doi.org/10.1093/ nutrit/nuv107. e-pub ahead of print 2016/04/02.

11. Yates AA, Schlicker SA, Suitor CW. Dietary reference intakes: the new basis for recommendations for calcium and related nutrients, B vitamins, and choline. J Am Dietetic Assoc. 1998;98:699-706. https://doi.org/10.1016/S0002-8223(98)00160-6. e-pub ahead of print 1998/06/17.

12. Institute of Medicine Standing Committee on the Scientific Evaluation of Dietary Reference I, its Panel on Folate OBV, Choline. The National Academies Collection: Reports funded by National Institutes of Health. In: Dietary Reference Intakes for Thiamin, Riboflavin, Niacin, Vitamin B(6), Folate, Vitamin B(12), Pantothenic Acid, Biotin, and Choline. National Academies Press
(US) Copyright (C) 1998, National Academy of Sciences.: Washington (DC), 1998.

13. Turck D, Bresson JL, Burlingame B, Dean T, Fairweather-Tait S, Heinonen $\mathrm{M}$ et al. Dietary reference values for thiamin. EFSA Journal 2016; 14, https://doi.org/10.2903/j.efsa.2016.4653.

14. MacLean LD, Rhode BM, Shizgal HM. Nutrition following gastric operations for morbid obesity. Ann Surg. 1983;198:347-55. epub ahead of print 1983/09/01.

15. Vahid F, Faghfoori Z, Davoodi SH. The impact of the disease trend on the macro and micro-nutrients intake in patients with gastric cancer. Nutr cancer. 2020;72:1036-42. https://doi.org/ $10.1080 / 01635581.2019 .1669677$. e-pub ahead of print 2019 / $10 / 02$.

16. Ferreira IB, Marinho Eda C, Custódio ID, Gontijo CA, Paiva CE, Crispim CA, et al. Food intake and the nutritional status of women undergoing chemotherapy. Cienc saude coletiva. 2016;21:2209-18. https://doi.org/10.1590/1413-81232015217.05412015. e-pub ahead of print 2016/07/08.

17. Sechi G, Serra A. Wernicke's encephalopathy: new clinical settings and recent advances in diagnosis and management. Lancet Neurol. 2007;6:442-55. https://doi.org/10.1016/S1474-4422(07) 70104-7. e-pub ahead of print 2007/04/17.

18. Harper C, Gold J, Rodriguez M, Perdices M. The prevalence of the Wernicke-Korsakoff syndrome in Sydney, Australia: a prospective necropsy study. J Neurol Neurosurg Psychiatry. 1989;52:282-5. e-pub ahead of print 1989/02/01.

19. Onishi H, Ishida M, Toyama H, Tanahashi I, Ikebuchi K, Taji Y, et al. Early detection and successful treatment of Wernicke encephalopathy in a patient with advanced carcinoma of the external genitalia during chemotherapy. Palliat Support Care. 2016;14:302-6. https://doi.org/10.1017/s1478951515000875. epub ahead of print 2015/12/15.

20. Onishi H, Sugimasa Y, Kawanishi C, Onose M. Wernicke encephalopathy presented in the form of postoperative delirium in a patient with hepatocellular carcinoma and liver cirrhosis: a case report and review of the literature. Palliat Support Care. 2005;3:337-40. e-pub ahead of print 2006/10/17.

21. Isenberg-Grzeda E, Alici Y, Hatzoglou V, Nelson C, Breitbart W. Nonalcoholic thiamine-related encephalopathy (Wernicke-Korsakoff Syndrome) among inpatients with cancer: a series of 18 cases. Psychosomatics. 2016;57:71-81. https://doi.org/10.1016/j. psym.2015.10.001. e-pub ahead of print 2016/01/23.

22. Galvin R, Brathen G, Ivashynka A, Hillbom M, Tanasescu R, Leone MA. EFNS guidelines for diagnosis, therapy and prevention of Wernicke encephalopathy. Eur J Neurol. 2010;17:1408-18. https://doi.org/10.1111/j.1468-1331.2010.03153.x. e-pub ahead of print 2010/07/21.

23. Victor M, Adams RD, Collins GH. The Wernicke-Korsakoff syndrome. A clinical and pathological study of 245 patients, 82 with post-mortem examinations. Contemp Neurol Ser. 1971;7:1-206. e-pub ahead of print 1971/01/01.

24. Onishi H, Ishida M, Tanahashi I, Takahashi T, Taji Y, Ikebuchi K, et al. Wernicke encephalopathy without delirium in patients with cancer. Palliat Support Care. 2018;16:118-21. https://doi.org/10. 1017/s1478951517000360. e-pub ahead of print 2017/05/04.

25. Harper CG, Giles M, Finlay-Jones R. Clinical signs in the Wernicke-Korsakoff complex: a retrospective analysis of 131 cases diagnosed at necropsy. J Neurol Neurosurg Psychiatry. 1986;49:341-5. e-pub ahead of print 1986/04/01.

26. Wada T, Wada M, Onishi H. Characteristics, interventions, and outcomes of misdiagnosed delirium in cancer patients. Palliat Support Care. 2010;8:125-31. https://doi.org/10.1017/ s1478951509990861. e-pub ahead of print 2010/03/24.

27. American Psychiatric Association. Diagnostic and Statistical Manual of Mental Disorders 5th edition. Washington DC: American Psychiatric Publishing; 2013. 
28. Oken MM, Creech RH, Tormey DC, Horton J, Davis TE, McFadden ET, et al. Toxicity and response criteria of the Eastern Cooperative Oncology Group. Am J Clin Oncol. 1982;5:649-55. e-pub ahead of print 1982/12/01.

29. Pourhassan M, Biesalski HK, Angersbach B, Lueg G, Klimek C, Wirth R. Prevalence of thiamine deficiency in older hospitalized patients. Clin Interv Aging. 2018;13:2247-50. https://doi.org/10. 2147/cia.s183102. e-pub ahead of print 2018/11/23.

30. Isenberg-Grzeda E, Shen MJ, Alici Y, Wills J, Nelson C, Breitbart W. High rate of thiamine deficiency among inpatients with cancer referred for psychiatric consultation: results of a single site prevalence study. Psycho-Oncol. 2017;26:1384-9. https://doi.org/10. 1002/pon.4155. e-pub ahead of print 2016/05/27.

31. Sechi G, Batzu L, Agro L, Fois C. Cancer-related Wernicke-Korsakoff syndrome. Lancet Oncol. 2016;17:e221-e222. https://doi.org/ 10.1016/s1470-2045(16)30109-7. e-pub ahead of print 2016/06/15.
32. Aksoy M, Basu TK, Brient J, Dickerson JW. Thiamin status of patients treated with drug combinations containing 5fluorouracil. Eur J Cancer. 1980;16:1041-5. e-pub ahead of print 1980/08/01.

33. Basu TK, Aksoy M, Dickerson JW. Effects of 5-fluorouracil on the thiamin status of adult female rats. Chemotherapy. 1979;25:70-76. e-pub ahead of print 1979/01/01.

34. Onishi H, Ishida M, Takahashi T, Taji Y, Ikebuchi K, Furuya D, et al. Wernicke encephalopathy without delirium that appeared as agitation in a patient with lung cancer. Palliat Support Care. 2018;16:800-2. https://doi.org/10.1017/s1478951518000226. epub ahead of print 2018/05/12.

35. Onishi H, Ishida M, Tanahashi I, Takahashi T, Taji Y, Ikebuchi K et al. Subclinical thiamine deficiency in patients with abdominal cancer. Palliat Support Care 2017: 1-3. e-pub ahead of print 2017/12/27; https://doi.org/10.1017/s1478951517000992. 